\title{
Diseño y elaboración de un multimedia educativo para el desarrollo de la producción oral inglesa
}

Olmedo Bula Villalobos' \& Jenaro Alberto Díaz-Ducca²

1. Profesor, Programa de Enseñanza del Inglés I y II Ciclos, Universidad Estatal a Distancia, Costa Rica

obula@uned.ac.cr

2. Profesor, Programa de Enseñanza del Inglés I y II Ciclos, Universidad Estatal a Distancia, Costa Rica

jdiazd@uned.ac.cr

Recibido: 16 de enero del 2018

Corregido: 13 de febrero del 2018

Aceptado: 05 de marzo del 2018

\section{Resumen}

El artículo examina el proceso de diseño y elaboración de un multimedia educativo para el desarrollo de la producción oral en un contexto de enseñanza del inglés como lengua extranjera (ILE). El recurso fomenta la competencia oral al enfocarse en una función fundamental en el proceso de adquisición del idioma inglés: la descriptiva. En cuanto a los tópicos del recurso multimedia, este se cimenta sobre cuatro categorías descriptivas generales: gente, lugares, casas, y animales. Asimismo, dicho producto tecnológico busca ofrecer una fase de presentación, una de práctica controlada y otra de producción. Este artículo contiene siete secciones en donde se considera el proceso de producción de un recurso multimedia; es decir, se provee un análisis de los conceptos e implicaciones más significativos. Finalmente, se ofrecen unas conclusiones pertinentes y reflexivas sobre el proceso.

Palabras clave: educación multimedia - diseño de materiales multimedia - educación a distancia TESOL - enseñanza del inglés - TEFL - producción oral

\section{Abstract \\ Design and Production of an Educational Multimedia for the Development of English Oral Production}

This article goes over the design and production process of an educational multimedia for the development of oral production within an English as a Foreign Language context (EFL). This multimedia fosters oral production by focusing on a pivotal function of the English language: describing people and things. Regarding the topics of the multimedia, this is based on four general descriptive categories: people, places, housing, and animals. Likewise, this learning resource offers a presentation, controlled practice, and a production stage. This article is divided into seven sections where the production process of an educational multimedia is considered - that is, an analysis of major concepts and implications is provided. Finally, some thought-provoking conclusions are offered.

Key words: multimedia - design of multimedia - online education - TESOL - teaching of English TEFL - oral production 
Cuando el usuario emplea un material interactivo se establece una comunicación entre el sujeto y la máquina; una interacción resultante de la presentación de unos estímulos a través del ordenador, ante

los cuales el sujeto emite una determinada respuesta, a la que el programa reacciona presentando una nueva situación perceptiva.

(Estebanell, 2002, p. 27)

\section{INTRODUCCIÓN}

La tecnología permea todo nuestro quehacer diario, forma parte casi inherente de nuestra cotidianidad. Los procesos educativos no escapan a esta realidad. La incursión de implementos tecnológicos ha influenciado significativamente las propuestas metodológicas y evaluativas. En el campo de la enseñanza del inglés como lengua extranjera (ILE) se han incorporado la utilización de laboratorios, computadores, grabadoras y equipo multimedia, con niveles aceptables de éxito en las últimas dos décadas.

Ahora bien, el lenguaje es una característica que identifica a los seres humanos; es decir, subyace la naturaleza misma de la condición humana. Esta distingue a seres con raciocinio de otros seres vivos y permite la comunicación sobre aspectos culturales, sociales, políticos, históricos y económicos. Asimismo, la producción oral es un constructo lingüístico fundamental del lenguaje que permite el intercambio, la apropiación, la discusión y el análisis de ideas e información. Particularmente, en el campo de la enseñanza del inglés como lengua extranjera, el desarrollo del constructo lingüístico es clave para desarrollar la competencia comunicativa del estudiantado.

Con base en lo anterior, este proyecto educativo se concretó en un recurso multimedia que permite el desarrollo de la producción oral y la competencia comunicativa del estudiantado de nivel intermedio. El recurso multimedia fomenta la competencia oral al enfocarse en una función fundamental en el proceso de adquisición del idioma inglés: la descriptiva. En cuanto a los tópicos del recurso multimedia, estos se cimentan sobre cuatro categorías descriptivas generales: gente, lugares, casas, y animales.

Finalmente, el producto tecnológico busca ofrecer una fase de presentación, una de práctica controlada y otra de producción (estas dos últimas con realimentación). Si se toma en cuenta que una efectiva medicación pedagógica en entornos virtuales e híbridos de aprendizaje se basa en la interacción docente-estudiante, estudiante-estudiante y estudiante-contenido, entonces la utilización de un recurso multimedia, como el que aquí se analiza, adquiere particular importancia para que el aprendizaje sea significativo y colaborativo. En este sentido, Fidalgo (2009) explica que "Se ha demostrado que con las tecnologías multimedia es más fácil alcanzar un objetivo; es decir, cuantos más canales de información se utilicen, más fácil será de alcanzar el objetivo. Este es el verdadero éxito de los sistemas multimedia [...]" (p. 4).

El objetivo del artículo es exponer las distintas etapas del diseño y elaboración de un multimedia educativo para la promoción de la producción oral mediante un análisis de los conceptos e implicaciones más significativos. A continuación, se detallan las secciones de este artículo: revisión de la literatura y elementos para el diseño y elaboración del multimedia educativo. Finalmente, se brindan unas conclusiones reflexivas sobre el tema. 


\section{REVISIÓN DE LA LITERATURA}

\section{Multimedia y objetos de aprendizaje}

La incorporación de las computadoras en la enseñanza es un proceso de varias décadas atrás. En este sentido, ya sea para la enseñanza a distancia (mediada por tecnología), o bien, la presencial en el aula (la que se ha considerado como "tradicional"), la creación de materiales audiovisuales o multimedia se ha convertido en un recurso muy valioso. Como nos dicen McGreal y Elliott (2008), el multimedia "incorpora texto, gráficos y medios de audio [...] y los combina, usando una computadora" (p. 144).

Por otro lado, los objetos de conocimiento (también llamados de aprendizaje), son "objetos discretos que se pueden integrar en las lecciones" (McGreal y Elliott, 2008, p. 158), que pueden ser multimedia, tienen la ventaja de poder reutilizarse $y$, en algunos casos, dependiendo de restricciones como la propiedad intelectual, o la capacidad de redes o servidores, se pueden distribuir o compartir.

Según Latapie (2007), los objetos multimedia se sustentan en el concepto de los canales de procesamiento de información separados, según la psicología cognoscitiva. Si bien la autora ofrece dos aproximaciones al término, nos limitaremos al llamado Modo de presentación, que se basa en la teoría de Codificación Dual de Paivio. Así, existen dos canales por los cuales la información se le presenta al estudiantado: el verbal, que procesa las palabras escritas y oídas, y el no verbal, que procesa imágenes y sonidos (efectos, música, etcétera).

Entre las características principales de los multimedia, Duarte (en Casal, Fernández y Cebreiro, 2003) apunta:

TABLA 1

Características de los multimedia

\begin{tabular}{ll}
\hline Flexibilidad: & permiten abordar la información desde diferentes perspectivas. \\
\hline Funcionalidad: & se adaptan a los contenidos y niveles de los estudiantes. \\
\hline Multidimensionalidad: & permiten la creatividad y una actitud activa del estudiante. \\
\hline Dinamismo: & los estudiantes abordan la información según sus estilos de aprendizaje. \\
\hline Interactividad: & los estudiantes establecen una relación activa con el multimedia. \\
\hline Acceso multiuso: & el multimedia puede usarse y volverse a usar casi indefinidamente. \\
\hline
\end{tabular}

Fuente: Duarte (en Casal, Fernández y Cebreiro, 2003, p. 210)

Como vemos en la tabla 1, estas cualidades permiten utilizar los multimedia en el aula virtual o presencial, de diferentes maneras y en diferentes momentos, de modo que se potencien el aprendizaje significativo y la comunicación dentro de un contexto constructivista. Estos elementos de la enseñanza los elaboraremos más adelante.

Enunciaremos tanto las ventajas como las desventajas de los multimedia. Primeramente, y como señala Fidalgo (2009), las ventajas son claras: "Se ha demostrado que la utilización de múltiples canales de información combinados para conseguir un mismo objetivo ayuda a lograrlo" (p. 5). Otra ventaja que se puede mencionar es que los diferentes estímulos (imágenes, texto, sonido) hacen el tema más atractivo para el estudiantado acostumbrado a los medios audiovisuales y digitales: Internet, televisión, videos. A la vez, poseen claras ventajas pedagógicas, como nos señalan Clark y Rossett: "Los estudiantes que 
usaron un curso basado en objetos (de aprendizaje) disfrutaron de una disminución de $41 \%$ en el tiempo requerido para completar la tarea" (en McGreal y Elliott, 2008, p. 159).

Por otro lado, Fidalgo (2009) menciona una de las desventajas más comunes de los multimedia:

"No se suelen adaptar a la situación concreta educativa (necesidades del profesor) y por otro lado la forma de transmitir ese conocimiento no se adapta a la forma de asimilarlo por el alumno" (p. 6), tales como los estilos de aprendizaje, relevancia, atractivo visual, actualidad, entre otros.

Es decir, pueden ser difíciles de seguir (sobrecargados visual o cognitivamente), desactualizados, descontextualizados, poco atractivos, o simplemente aburridos. Para evitar esto, se hace fundamental un diseño cuidadoso que responda no solo a las necesidades del profesorado y el estudiantado, a su contexto, realidad educativa, sino que se sigan una serie de principios básicos para el diseño de materiales útiles que promuevan verdaderamente el aprendizaje significativo.

\section{Principios para el diseño de objetos multimedia}

Tanto para el diseño como para la incorporación de objetos multimedia en el aula virtual o presencial, los principios señalados por Mayer y recopilados por Fahy (2008) se tornan fundamentales si se quiere tener un producto audiovisual que ayude a alcanzar los objetivos pedagógicos. Procedemos a enumerarlos y resumirlos en la tabla 2:

TABLA 2

Principios para el diseño de materiales multimedia

\begin{tabular}{ll}
\hline 1- Principio multimedial & $\begin{array}{l}\text { El uso tanto de texto más elementos visuales es más provechoso } \\
\text { que el uso exclusivo de texto. }\end{array}$ \\
\hline 2- Principio de la contigüidad espacial & $\begin{array}{l}\text { La cercanía de palabras e imágenes juntas en la página es mejor } \\
\text { para el aprendizaje. }\end{array}$ \\
\hline 3- Principio de la contigüidad temporal & $\begin{array}{l}\text { La presentación simultánea de palabras e imágenes fomenta el } \\
\text { aprendizaje. }\end{array}$ \\
\hline 4- Principio de coherencia & $\begin{array}{l}\text { Se deben eliminar palabras o imágenes redundantes o fuera de } \\
\text { contexto. }\end{array}$ \\
\hline 5- Principio de modalidad & $\begin{array}{l}\text { El uso de animaciones y narraciones sonoras es más efectivo que el } \\
\text { uso de animaciones y texto. }\end{array}$ \\
\hline 6- Principio de redundancia & $\begin{array}{l}\text { Debido a las limitaciones del cerebro para absorber varios estímulos } \\
\text { simultáneamente, el uso de narraciones y animaciones es más efec- } \\
\text { tivo que usar otros elementos juntos. }\end{array}$ \\
\hline 7- Principio de diferencias individuales & $\begin{array}{l}\text { Los efectos del diseño se usarán dependiendo del nivel de conoci- } \\
\text { miento e instrucción de los estudiantes, así como de su capacidad } \\
\text { para procesar imágenes. }\end{array}$ \\
\hline
\end{tabular}

Fuente: Elaboración propia a partir de Fahy $(2008$, p. 172)

Si bien lo ideal es incorporar todos estos principios durante el diseño del objeto multimedia, no necesariamente se aplicarán todos, considerando, como se señaló anteriormente, la pertinencia y la relevancia según el contexto de la enseñanza, las características del profesorado y el estudiantado, y los objetivos pedagógicos. 
Algunas consideraciones importantes son el respeto de los derechos de autor al incorporar imágenes, textos o sonidos, la necesidad de capacitar al profesorado o al estudiantado para su uso, los costos de producción altos, así como la necesidad de reestructurar el currículo según el caso (Umaña, Salas y Berrocal, s.f., p. 111).

\section{El socioconstructivismo y las interacciones en la educación mediada por computadoras}

El Ilamado socioconstructivismo se basa principalmente en las teorías de Vygotsky, establece que el aprendizaje se presenta en un contexto social de interacción entre el estudiantado y el profesorado. De esta manera, el conocimiento no se transmite, sino que se construye en un proceso activo de intercambio y crecimiento constante. El proceso requiere de un andamiaje cognitivo o pedagógico, que puede presentarse por parte del profesorado o de los compañeros. Como nos recuerdan Campbell y Schwier (2014), la responsabilidad del aprendizaje recae sobre el estudiantado, y el papel del instructor es el de facilitador, quien "está en diálogo continuo con el estudiante, haciendo preguntas que motivan al estudiante a profundizar, retándole a usar su experiencia personal como punto de partida para encontrarle sentido al mundo" (p. 359).

Las interacciones entre el estudiantado y el profesorado en el caso de la enseñanza mediada por computadoras, o en la enseñanza a distancia, adquieren matices específicos, ya que entre otras funciones, "permiten varias formas de participación y comunicación, y ayudan al aprendizaje significativo" (Anderson, 2008, p. 55). Específicamente, las interacciones son las siguientes: estudiante-estudiante: fomentan la colaboración y la adquisición de habilidades sociales; estudiante-profesor: incluye comunicación síncrona y asíncrona, por diversos medios; y estudiante-contenido: o multimedia, en este caso, y permite la interactividad con el recurso, así como la adaptación a las necesidades del estudiantado (Anderson, 2008).

\section{Enfoque comunicativo en la enseñanza de la producción oral}

En la enseñanza del inglés como lengua extranjera (ILE), ya sea en la enseñanza presencial o en línea, al hablar de un enfoque comunicativo se enfatiza en "que se basa en la premisa de que, si el desarrollo de las habilidades comunicativas orales son el objetivo del aprendizaje en el aula, entonces la práctica comunicativa debe ser parte de ese proceso" (Hedge, 2000, p. 57). Entre sus principales características, se pueden citar que el idioma es un medio y no un fin (el énfasis recae en el mensaje y no en la forma); el estudiantado delimita el contenido según sus ideas u opiniones en juego; debe haber negociación de significado (los estudiantes interpretan el sentido y no dependen del profesor); la información que se intercambia no debe ser predecible; se dan procesos "normales" de comunicación (paráfrasis, improvisación); la corrección del profesorado debe ser mínima para no desviar la atención del mensaje (Hedge, 2000).

De tal modo, cuando se pretende enseñar destrezas orales de forma comunicativa, Bailey (2005) sugiere algunos principios para tener en cuenta: planear actividades que impliquen la negociación de significado (poniéndole atención al vocabulario, gramática, pronunciación correctas); diseñar actividades transaccionales e interpersonales (transaccionales como el intercambio de información, o llevar a cabo alguna operación o tarea, interpersonales como el desarrollo de relaciones sociales); personalizar el contenido de las actividades (ajustarlas a sus intereses, necesidades, contexto social y cultural). Por lo tanto, cuando hay un intercambio auténtico de información, ya sea para fines sociales o transaccionales, ya sea virtualmente o en persona, el estudiantado estará usando la lengua meta de una manera comunicativa 
y tan cercana a la vida real como sea posible. Como se plantea, en el caso de un objeto multimedia, también debe considerarse el uso comunicativo, tanto en su diseño como en su implementación durante la enseñanza a distancia o presencial.

\section{ELEMENTOS PARA EL DISEÑO Y ELABORACIÓN DEL MULTIMEDIA EDUCATIVO}

\section{Objetivos para el diseño y elaboración del multimedia}

Los siguientes son los objetivos que sirvieron de guía en el proyecto de diseño y elaboración del multimedia educativo.

\section{Objetivo general}

- Desarrollar un recurso multimedia que promueva la producción oral del idioma inglés como lengua extranjera del estudiantado de nivel intermedio.

\section{Objetivos específicos}

- Mejorar la competencia lingüística en diversos contextos.

- Describir características y rasgos basados en los tópicos: gente, casas, lugares y animales.

- Proveer patrones adecuados de gramática y pronunciación cuando se describe.

\section{Necesidad educativa que se atendió}

Los docentes son los responsables de brindar una educación integral y de llevar a la práctica el conocimiento especializado adquirido a través de una formación comprometida con la sociedad, con el fin de satisfacer las necesidades de una población creciente, que posibilite el progreso, la superación, el desarrollo y la igualdad de oportunidades. La comunicación es uno de los procesos fundamentales en la historia del ser humano y como seres sociales debemos procurar poseer las herramientas y destrezas necesarias para garantizar la calidad de la comunicación con nuestros semejantes. En este sentido, Freire (1976) comenta que:

La educación es comunicación, es diálogo, en la medida en que no es la transferencia del saber, sino un encuentro de sujetos interlocutores, que buscan la significación de los significados. La comunicación no es la transferencia o transmisión de conocimientos de un sujeto a otro, sino su coparticipación en el acto de comprender la significación de los significados es una comunicación que se hace críticamente. (p. 85)

Lo anterior expresa que la comunicación y la educación están íntimamente relacionadas; es decir, no puede existir una sin la otra. Además, el proceso docente educativo es comunicativo, pues el profesorado y el estudiantado participan activamente en la solución de las tareas y en la adquisición de nuevos 
conocimientos. Por lo tanto, aprenden unos de otros durante su ejecución, se va a producir un encuentro entre los sujetos que trascenderá en un nuevo saber, en una acción transformadora.

Finalmente, para los estudiantes y docentes es vital comprender las sutilezas y complejidades de la habilidad del habla y sus implicaciones sociolingüísticas para que se desarrolle efectivamente. Es un comportamiento tan natural y común que no se toman en cuenta un sinnúmero de aspectos físicos, mentales, psicológicos, sociolingüísticos y culturales que necesariamente deben conjugarse efectivamente cuando hablamos (Bailey, 2005).

\section{Público meta del multimedia}

Generalmente el estudiantado de nivel intermedio está compuesto por adultos-jóvenes y adultos cuyas edades oscilan entre los 18 y 55 años de edad. La gran mayoría tiene conocimientos básicos de sistemas operativos y programas computacionales. Su nivel de inglés va del B1 al B2 de acuerdo al Marco Común Europeo de Referencias para las Lenguas. En cuanto al nivel de escolaridad, se presenta una gama desde secundaria completa hasta diversos niveles universitarios. De hecho, estudian inglés con finalidades académicas y laborales y comparten el idioma español como lengua materna (L1).

\section{Enfoque pedagógico que sustentó el diseño del multimedia}

Para el desarrollo del recurso multimedia se utilizó el enfoque pedagógico constructivista cuya razón de ser se sustenta en que el estudiantado conozca su realidad y participe activamente en su apropiación. El propósito del multimedia educativo no es la transmisión de conocimientos, sino la creación de situaciones de aprendizaje que permitan al estudiantado la construcción e interpretación propia de la información con la finalidad de comprenderla. La docente propicia espacios de aprendizaje que promueven y permitan al estudiantado un pensamiento crítico que contribuya a la restructuración de los esquemas mentales, constituyéndose en guía u orientador del proceso de enseñanza, por ende, los conocimientos previos y la experiencia del estudiantado se consideran para la construcción de nuevas competencias.

La intervención del estudiantado en la construcción de su aprendizaje le permite un desarrollo cognitivo que avanza de estados de conocimiento de menor validez a estados de conocimiento de mayor validez, esto es, la incorporación en la estructura mental de conocimientos simples sobre los cuales reestructura la adquisición y comprensión de conocimientos cada vez más complejos, con la finalidad de comprender el mundo que le rodea sobre la base de un aprendizaje significativo. En este sentido, Pachano y Terán (s.f.) nos comentan:

En la práctica pedagógica, la posibilidad de enriquecer nuestro conocimiento, ampliar nuestras perspectivas y desarrollarnos como personas, están determinadas en buena medida, por la comunicación [...] así como por la interacción que ocurre entre el docente y el alumno y entre los propios alumnos, los contenidos y materiales de aprendizaje. En este sentido [...] el docente debe promover el trabajo cooperativo y colaborativo (p. 2).

De acuerdo con Serrano y Pons (2011), el constructivismo sociocultural de Vygotsky "propone a una persona que construye significados actuando en un entorno estructurado e interactuando con otras personas de forma intencional" (p. 8). De esta manera, un aprendizaje colaborativo y cooperativo se presenta como estrategias constructivistas que a través del empleo de las TIC potencian la consecución cualitativa de los objetivos propuestos. 


\section{Descripción del multimedia educativo}

Se espera que el recurso multimedia refuerce la adquisición y práctica de vocabulario y constructos gramaticales significativos en el idioma inglés, que permita al estudiantado la capacidad de describir personas, casas, lugares, y animales adecuadamente. Consecuentemente, el idioma del recurso es el inglés. El recurso multimedia tiene una página de entrada con los siguientes elementos: título del recurso, metáfora sugerida, botón "créditos", botón "copyright", botón de información sobre el programa, botón "nuestras categorías", y botón "salida". Los botones más relevantes de la página de entrada son Sobre el Programa, ya que se realiza una descripción general del recurso multimedia y Nuestras Categorías, pues contiene las categorías y subcategorías que describen la esencia gramatical y de vocabulario. Finalmente, cada módulo se subdivide en las siguientes categorías: 1-Descripción de personas (apariencia, estatura contextura y tipo de cabello), 2-Descripción de alojamientos (apartamentos y casas), 3-Descripción de lugares (cómo son y cosas para ver y hacer), 4-Descripción de animales (domésticos, salvajes, y de granja).

El recurso fue diseñado para utilizarse en cualquier momento y en cualquier lugar de manera que promueva la autorregulación del aprendizaje. La herramienta multimedia inicia con una página en la que se aprecia el tema y la metáfora sugerida. Al presionar el botón "nuestras categorías", se despliega un menú de entrada donde el estudiantado podrá elegir entre los cuatro conceptos principales. Cada categoría posee botones de interacción que presentan una progresión lógica y basada en la propuesta metodológica del recurso multimedia.

En cuanto a la estructuración del diseño, los módulos del recurso multimedia presentan un contenido gramatical, visual, auditivo y de vocabulario específico. Cada categoría contiene oraciones de presentación, un enfoque gramatical, práctica de selección única, ejercicios de producción y respuestas de realimentación.

- Objetivo terminal: al finalizar la utilización del recurso multimedia, el estudiantado será capaz de describir personas, casas, lugares y animales utilizando diversas características en forma oportuna y adecuada.

- Aprendizaje previo requerido: el estudiantado tendrá un conocimiento básico de constructos lingüísticos y culturales. Por ejemplo, no se utiliza vocabulario específico que, aunque sirve para describir personas, podría conllevar connotaciones ofensivas o despectivas (por ejemplo, los vocablos fat o hot en inglés). A continuación se detallan temas gramaticales y de pronunciación tales como presente simple, presente continuo, verbo ser o estar, comparativos, superlativos, verbos comunes, patrones de entonación y acento tónico de palabras y oraciones.

- Adquisición de conocimiento: ocurre mediante un andamiaje pedagógico que se va construyendo sobre las cuatro categorías del recurso multimedia. La incorporación de texto, audio y video es fundamental durante la fase de presentación. Finalmente, se espera que la asociación de conocimiento nuevo con conocimiento previo genere el nuevo aprendizaje.

- Sistema de refuerzo y evaluación: consiste básicamente en páginas que contienen realimentación positiva cuando el desempeño ha sido satisfactorio y realimentación negativa cuando el desempeño no ha sido el esperado. Es decir, una evaluación formativa.

Además, la metáfora pedagógica del recurso multimedia es una figura de un árbol cerebro. La elección de la metáfora se debe a que nuestro cerebro se asemeja a un gran árbol cargado de información que se relaciona con conocimientos nuevos para realizar descripciones utilizando el lenguaje como un medio. El constructo se transmite en forma deductiva al utilizar el recurso multimedia. 
Asimismo, la herramienta seleccionada para el montaje del multimedia educativo es eXeLearning, ya que es de acceso libre y compatible con la mayoría de los navegadores. Finalmente, eXeLearning permite exportar el archivo para luego incorporarlo en una LMS o bien como un archivo ZIP para trabajarse en forma independiente. En cuanto a la letra, se utilizó Arial 14 debido a su tipografía clara y sencilla. La propuesta de diseño gráfico se puede visualizar directamente en el multimedia educativo. Como la población meta son estudiantes adultos y adultos jóvenes, se escogió la plantilla FPD-MEDU de eXeLearning por su sobriedad y sencillez. Además, es absolutamente blanca y no compite con las imágenes utilizadas en el recurso multimedia. Finalmente, las imágenes fueron tomadas de www.pixabay.com. Todos los elementos anteriormente descritos pueden apreciarse en la figura 1.

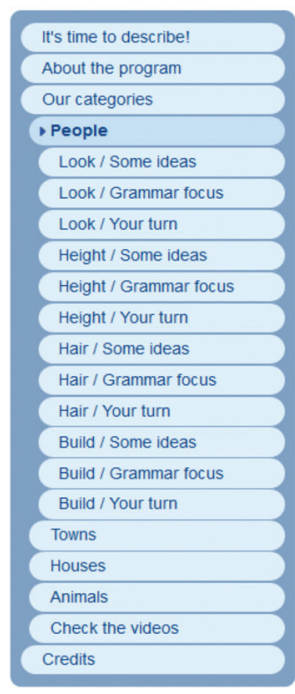

\section{People}

Figura 1. Menú del multimedia educativo. Fuente: Tomado del multimedia educativo.

En cuanto a la metodología, el multimedia educativo está diseñado para que el estudiantado de nivel intermedio lo use de manera individual o grupal, en el salón de clase o en la casa, se constituye así la interactividad en el medio que les permite interiorizar significativamente los conceptos al asociarlos con las imágenes correspondientes. El acceso constante a un instrumento práctico le permite al estudiante un reforzamiento del proceso de enseñanza y aprendizaje.

Asimismo, la metodología por utilizar en este recurso multimedia es el enfoque comunicativo. Básicamente, el enfoque se implementa en la enseñanza de idiomas ya enfatiza en la interacción comunicativa como medio y objetivo; es decir, en la comunicación como objetivo final. La metodología contempla los siguientes pasos:

Presentación: aquí se introduce el vocabulario, frases y contenidos gramaticales por utilizar en la fase de producción. Se presentan en forma inductiva o deductiva.

Práctica controlada: en esta sección se repasan los constructos más importantes que se presentaron en la fase anterior por medio de la ejecución y revisión de prácticas. La participación activa del estudiante es fundamental. Usualmente, se aplican modelos comunicativos que sirven de base para la fase de producción. 
Producción: con base en lo presentado y lo practicado, el estudiantado implementa técnicas y estrategias de aprendizaje para ejecutar tareas basadas en actividades cotidianas (juegos de roles, entrevistas, y presentaciones, entre otros).

En cuanto al diseño comunicacional, los dispositivos de entrada son el ratón y el teclado, y los dispositivos de salida son la pantalla y los parlantes o audífonos. Con respecto al diseño computacional, el recurso multimedia se compone de diez secciones: página de entrada, créditos, copyright, sobre el programa, nuestras categorías, presentación, enfoque gramatical, práctica, producción y realimentación.

El diagrama de navegación consiste en un menú principal con acceso a las diferentes categorías. Una vez en las diferentes secciones, los estudiantes pueden acceder a módulos específicos por medio de botones de acción e hipervínculos. A continuación se ilustran los diagramas de navegación.

TABLA 3

Diagrama página de entrada
TABLA 4

Diagrama sobre el programa

\begin{tabular}{|c|c|}
\hline PÁGINA DE ENTRADA & SOBRE EL PROGRAMA \\
\hline $\begin{array}{l}\text { Créditos } \\
\text { Copyright } \\
\text { Sobre el programa } \\
\text { Nuestras categorías } \\
\text { Salir }\end{array}$ & $\begin{array}{l}\text { Descripción general del recurso multimedia } \\
\text { Página de entrada } \\
\text { Nuestras categorías } \\
\text { Salir }\end{array}$ \\
\hline Fuente: Elaboración propia & Fuente: Elaboración propia \\
\hline $\begin{array}{c}\text { TABLA } 5 \\
\text { Diagrama nuestras categorías }\end{array}$ & $\begin{array}{c}\text { TABLA } 6 \\
\text { Diagrama descripción de personas }\end{array}$ \\
\hline NUESTRAS CATEGORÍAS & DESCRIPCIÓN DE PERSONAS \\
\hline $\begin{array}{l}\text { Descripción de personas } \\
\text { Descripción de casas } \\
\text { Descripción de lugares } \\
\text { Descripción de animales } \\
\text { Página de entrada } \\
\text { Salir }\end{array}$ & $\begin{array}{l}\text { Apariencia } \\
\text { Altura } \\
\text { Contextura } \\
\text { Cabello } \\
\text { Página de entrada } \\
\text { Ir atrás } \\
\text { Salir }\end{array}$ \\
\hline Fuente: Elaboración propia & Fuente: Elaboración propia \\
\hline $\begin{array}{c}\text { Tabla } 7 \\
\text { Diagrama descripción de casas }\end{array}$ & $\begin{array}{c}\text { Tabla } 8 \\
\text { Diagrama descripción de lugares }\end{array}$ \\
\hline DESCRIPCIÓN DE CASAS & DESCRIPCIÓN DE LUGARES \\
\hline $\begin{array}{l}\text { Departamentos } \\
\text { Casas } \\
\text { Página de entrada } \\
\text { Ir atrás } \\
\text { Salir }\end{array}$ & $\begin{array}{l}\text { Cómo son } \\
\text { Cosas por hacer-ver } \\
\text { Página de entrada } \\
\text { Ir atrás } \\
\text { Salir }\end{array}$ \\
\hline Fuente: Elaboración propia & Fuente: Elaboración propia \\
\hline
\end{tabular}


TABLA 9

Diagrama descripción de animales

\section{DESCRIPCIÓN DE ANIMALES}

Domésticos

Salvajes

Granja

Página de entrada

Ir atrás

Salir

Fuente: Elaboración propia

Como se observa, de la tabla 3 a la 5, los diagramas de navegación ofrecen información que sitúa al estudiantado en las generalidades del multimedia educativo. Fundamentado en la revisión de la literatura, en ellas se hace una descripción general de las categorías descriptivas del programa haciendo uso de texto, imágenes y audio. Además, las mismas corresponden a la fase de configuración del entorno. Asimismo, de la tabla 6 a la 9, se subdividen las categorías en subcategorías específicas que facilitan la función descriptiva del multimedia educativo. Las mismas corresponden a las fases de presentación, práctica controlada y producción. El desarrollo de las categorías se basa en un proceso constructivista que promueve un andamiaje lingüístico que le permite al estudiantado la adquisición del idioma inglés como lengua extranjera en forma escalonada e iterativa.

\section{Contenido del primer módulo: descripción de personas (apariencia)}

Para efectos explicativos e ilustrativos, a continuación se detallan los contenidos de un submódulo del multimedia educativo titulado Descripción de Personas (apariencia).

TABLA 10

Presentación del submódulo Apariencia

\begin{tabular}{|c|c|}
\hline Submódulo Apariencia & Presentación \\
\hline Título & Look \\
\hline Instrucciones & $\begin{array}{l}\text { Carefully read and listen to the following sentences. (Los estudiantes escucharán estas } \\
\text { instrucciones cuando pinchen el botón de audio). }\end{array}$ \\
\hline Estructura gramatical & $\begin{array}{l}\text { Simple present - verb to be } \\
\text { Thalia is pretty. } \\
\text { Javier Bardem is handsome. } \\
\text { The baby is cute. } \\
\text { Betty is ugly. }\end{array}$ \\
\hline Vocabulario a enfatizar & $\begin{array}{l}\text { Adjectives } \\
\text { pretty - handsome - cute - ugly }\end{array}$ \\
\hline Contenido visual & Ilustraciones de los personajes y/o actores \\
\hline Contenido auditivo & $\begin{array}{l}\text { Por medio de un botón de acción, los estudiantes podrán escuchar las siguientes } \\
\text { oraciones que serán grabadas por el autor del recurso multimedia en formato mp3. } \\
\text { Thalia is pretty. } \\
\text { Javier Bardem is handsome. } \\
\text { The baby is cute. } \\
\text { Betty is ugly. }\end{array}$ \\
\hline Botones de acción & Menú, ir atrás, enfoque gramatical, salir y audio \\
\hline
\end{tabular}

Fuente: Tomado del multimedia educativo. 
En la tabla 10 se especifican los contenidos que corresponden puntualmente a la etapa de presentación. Se observa cómo se cumple con las características de un multimedia educativo abarcadas en la revisión de la literatura, específicamente el dinamismo y la flexibilidad al ofrecer al estudiantado fuentes de comunicación diversas que se adaptan a distintos estilos de aprendizaje. Además, los contenidos son presentados en forma deductiva para lograr inferir las estructuras gramaticales y los patrones de pronunciación.

TABLA 11

Enfoque gramatical del submódulo Apariencia

\begin{tabular}{|c|c|}
\hline Submódulo Apariencia & Enfoque gramatical \\
\hline Título & Grammar Focus \\
\hline Instrucciones & $\begin{array}{l}\text { Carefully read and listen to the following explanation. (Los estudiantes escucharán } \\
\text { estas explicaciones cuando pinchen el botón de audio). }\end{array}$ \\
\hline Explicación & $\begin{array}{l}\text { 1. Use these adjectives after the verb to be AM-IS-ARE. } \\
\text { 2. Use the adjective HANDSOME to describe males. } \\
\text { 3. Use the adjective PRETTY to describe females. } \\
\text { Study the following example: } \\
\text { Antonio is HANDSOME. }\end{array}$ \\
\hline Vocabulario a enfatizar & $\begin{array}{l}\text { Adjectives } \\
\text { pretty - handsome }\end{array}$ \\
\hline Contenido visual & Ilustración del actor \\
\hline Contenido auditivo & $\begin{array}{l}\text { Por medio de un botón de acción, los estudiantes podrán escuchar la explicación y } \\
\text { la oración de ejemplo que serán grabadas por el autor del recurso multimedia en } \\
\text { formato mp3. } \\
\text { 1. Use these adjectives after the verb to be AM-IS-ARE. } \\
\text { 2. Use the adjective HANDSOME to describe males. } \\
\text { 3. Use the adjective PRETTY to describe females. } \\
\text { Study the following example: } \\
\text { Antonio is HANDSOME. }\end{array}$ \\
\hline Botones de acción & Menú, ir atrás, su turno, salir y audio \\
\hline
\end{tabular}

Fuente: Tomado del multimedia educativo.

También se detallan los contenidos que competen a la etapa de presentación. La diferencia con el cuadro anterior estriba en que los contenidos son presentados en forma explícita y directa, dirigiendo la atención del estudiantado a las formas de los contenidos de gramática, vocabulario y pronunciación. Además, se observa cómo se respetan los principios de un multimedia educativo que fueron analizados en la revisión de la literatura, concretamente los principios multimedial y modalidad, ya que se utiliza una combinación de texto, audio e imágenes. 
TABLA 12

Práctica controlada del submódulo Apariencia

\begin{tabular}{ll}
\multicolumn{1}{c}{$\begin{array}{c}\text { Submódulo Apariencia } \\
\text { Título }\end{array}$} & \multicolumn{1}{c}{ Práctica controlada } \\
Instrucciones & Choose the option that best completes the sentences. \\
\hline Oraciones & $\begin{array}{l}\text { Shakira is pretty / ugly. } \\
\text { The boys are pretty / handsome. }\end{array}$ \\
\hline Vocabulario por enfatizar & $\begin{array}{l}\text { Adjectives } \\
\text { pretty - handsome - ugly }\end{array}$ \\
\hline Contenido visual & Ilustración de la actriz y personajes \\
\hline Botones de acción & Menú, ir atrás, salir y opciones \\
\hline
\end{tabular}

Fuente: Tomado del multimedia educativo.

El recuadro anterior ilustra los contenidos que corresponden a la etapa de práctica controlada, absolutamente fundamental en el enfoque comunicativo para la producción oral, ya que fomenta un espacio para construir y asimilar conceptos gramaticales y patrones de pronunciación basados en modelos pertinentes. El andamiaje académico constituye una etapa vital para la adquisición del idioma inglés como lengua extranjera.

TABLA 13

Realimentación del submódulo Apariencia

\begin{tabular}{ll}
\hline Submódulo Apariencia & Realimentación positiva y negativa \\
\hline Oraciones & Yes, Shakira is very pretty / Ugly? No, she is pretty. Look again! \\
\hline Vocabulario por enfatizar & $\begin{array}{l}\text { Adjectives } \\
\text { pretty - ugly }\end{array}$ \\
\hline Contenido visual & Ilustraciones de la actriz \\
\hline Botones de acción & Menú, ir atrás y salir \\
\hline
\end{tabular}

Fuente: Tomado del multimedia educativo.

La tabla 13 describe los contenidos que atañen a la etapa de producción o desarrollo, constituye el objetivo terminal del multimedia educativo, que persigue una descripción general al establecer relaciones de conocimientos previos con los nuevos constructos sociolingüísticos; es decir, se establece una construcción que utiliza el idioma inglés como un medio comunicativo y no un fin en sí mismo, característica primordial del enfoque comunicativo (método comunicativo) que sirvió de base para el diseño e implementación del multimedia educativo. La realimentación pretende ofrecer una guía práctica sobre el desempeño del estudiantado en la función descriptiva.

A la vez, es importante mencionar que, con la finalidad de evaluar el recurso multimedia, se efectuó un proceso de pilotaje con cinco grupos de estudiantes de inglés de nivel intermedio y sus respectivos docentes. El objetivo principal del proceso era validar y mejorar el recurso educativo basado en la opinión de estudiantes y profesores, fase que tomó dos meses.

A continuación se especifican los detalles y resultados más relevantes. En el proceso participaron un total de 53 estudiantes y 5 docentes. Ante la pregunta: ¿Promueve el multimedia educativo la función 
descriptiva al hablar inglés? Un impresionante $96,22 \%$ manifestó que si la promovía. Es importante mencionar que para impedir confusiones entre el estudiantado, se evitó el uso de metalenguaje.

Otro resultado importante fue obtenido a través de la siguiente pregunta dirigida al profesorado: ¿Promueve el uso del multimedia educativo la función descriptiva al utilizar el idioma inglés como lengua extranjera? Un contundente $100 \%$ manifestó que efectivamente sí lo promovía. Es evidente que la validación obtenida ofrece altos niveles de satisfacción y confiabilidad en el multimedia educativo. Además, es interesante comentar que ante la pregunta: ¿Qué eventuales cambios incluiría usted en el multimedia educativo? Un significativo $56,60 \%$ del estudiantado manifestó que no realizaría ningún tipo de cambio. Al contrario, otro 28,30 sugirió la incorporación de personajes locales que fomentaran la identidad nacional. Dicha sugerencia fue aceptada e incorporada en la versión beta. Asimismo, en otras categorías como contenido, aspectos pedagógicos y técnicos, navegación e interactividad, diseño gráfico y funcionabilidad los resultados fueron altamente positivos y válidos al superar $85 \%$ en todos los casos. En definitiva, estos datos ofrecen un grado de validez y confiabilidad importante en el recurso. Finalmente, todo el ciclo de elaboración y diseño del multimedia educativo tuvo una duración de ocho meses.

\section{CONCLUSIONES}

Sin duda alguna, la fase de planeamiento del diseño de un recurso multimedia es imprescindible a la hora de tomar en cuenta las implicaciones teóricas lingüísticas y operativas del recurso. Comenzaremos refiriéndonos a los principios señalados por Fahy (2008) del cuadro 2 como inherentes al multimedia. Evidentemente, el recurso creado cumple con los principios multimediales de contigüidad espacial, temporal y de coherencia, pues los criterios dictan el uso mesurado, puntual y oportuno de las vías de estímulo del modo de presentación como las menciona Latapie (2007). En este sentido, queda muy claro que menos es más: simplicidad en el diseño y uso apropiado de los elementos verbales y no verbales (principio de no redundancia).

Por otro lado, el principio de las diferencias individuales, que se tomó en cuenta a la hora de seleccionar los contenidos y temas lingüísticos, se ha respetado también y nos lleva a las implicaciones pedagógicas y didácticas. Las implicaciones pueden presentar limitaciones tal y como quedó el objeto multimedia, pues el contexto tanto lingüístico como pedagógico del estudiantado y el tecnológico en el uso del recurso propiamente, nos condicionan en la utilidad potencial del multimedia visto como producto final. En otras palabras, un análisis exhaustivo de todas estas implicaciones se vuelve necesario para prever futuros inconvenientes y contratiempos en el aula. Mucho de esto, sin embargo, escapa de las manos de los diseñadores, por lo tanto le corresponderá enfrentarlo juntos al profesorado y al estudiantado, en el mejor de los casos. Pero, claramente, es una limitación que todos los objetos de aprendizaje, sean multimedia o no, exhiben.

Es decir, en un recurso multimedia la interactividad tal y como la menciona Duarte en el cuadro 1, es necesaria para el desarrollo de los objetivos. En este caso en particular, la producción oral dentro de un contexto constructivista se logra gracias a las interacciones estudiante-estudiante, estudiante-profesor, y principalmente estudiante-recurso. Asimismo, el uso de un recurso multimedia supone el desarrollo de nuevas estrategias pedagógicas y comunicativas, que en el caso de la enseñanza presencial y a distancia, exigen la intervención del profesor como guía y facilitador.

Por tanto, el multimedia es, como su nombre lo aclara, un medio y no un fin. Sus características de flexibilidad, multidimensionalidad, funcionalidad y dinamismo dependen tanto de la previsión y aplicación durante la etapa de diseño de estos criterios, como del uso y adaptación que hagan de él el profesorado y el estudiantado. Así, parte de la tarea ineludible de instructor y estudiante es buscar la extensión del 
recurso mediante otros que permitan complementarlo, enriquecerlo y aplicarlo a los objetivos de aprendizaje del aula, como aconsejan Campbell y Schwier (2014).

Hoy más que nunca, el internet es una fuente valiosísima de otros recursos que pueden adaptarse para este fin. Valga añadir que creemos firmemente en las posibilidades que nos ofrece la educación mediada por computadoras para la enseñanza del inglés: estas posibilidades son prácticamente infinitas, y le brindan una constelación de herramientas al profesorado, estudiantado y a los diseñadores de objetos multimedia para cumplir el objetivo de una enseñanza constructivista y significativa de la lengua.

No dudamos en que si bien el producto final pueda tener algunas limitaciones (breve extensión, restricción temática basada en la unidad y coherencia lingüística), su uso será de provecho en el aula si quien enseña brinda el andamiaje lingüístico y pedagógico en el aula, complementándolo con otros recursos y la interacción comunicativa en el aula presencial o virtual. Por tanto, nos parece que el pilotaje del material, así como la realimentación que pueda ofrecer el estudiantado, representan un insumo muy valioso para enriquecerlo y adaptarlo a las condiciones de cada grupo.

En nuestro caso, encontramos como principales limitaciones la rigidez en los contenidos, que hacen que materiales como el presente pierdan vigencia y novedad muy pronto. Por eso al utilizarse como referencia para basarse en la misma estructura con nuevos contenidos, mediante módulos y "previstas" para añadirle nuevos temas o ejercicios permite mayor flexibilidad en su implementación en el aula. Además, los recursos de uso público con licencias de Creative Commons, así como la capacitación del profesorado para que pueda editar el multimedia según su gusto y necesidades, son pasos que harán de la enseñanza a distancia un proceso más creativo, flexible y que garantice el aprendizaje significativo dentro de un contexto constructivista.

\section{REFERENCIAS}

Anderson, T. (2008). Towards a Theory of Online Learning. En Anderson, T. (Ed.), The Theory and Practice of Online Learning. Athabasca University Press: Edmonton.

Bailey, K. (2005). Practical English Language Teaching: Speaking. New York: McGraw Hill.

Campbell, K., \& Schwier, R. (2014). Major Movements in Instructional Design. En Zawacki-Richter, O. y Anderson, T. (Eds.), Online Distance Education: Towards a Research Agenda. Athabasca University Press: Edmonton.

Casal, L., Fernández, C., \& Cebreiro, B.(2003). Formación virtual para la formación continua: respondiendo a la demanda del mundo empresarial. En Aguiar, M.V., y Farray, J.I. (Eds) Sociedad de la información y cultura mediática. Netbiblo: Coruña. Recuperado de: https://books.google.co.cr/ books?id=W-E_mV4rSJ8C\&pg

Estebanell, M. (2002). Interactividad e interacción. Revista Latinoamericana de Tecnología Educativa, 1, 23-32.

Fahy, P. (2008). Characteristics of Interactive Online Learning Media. En Anderson, T. (Ed.), The Theory and Practice of Online Learning. Athabasca University Press: Edmonton.

Fidalgo, A. (2009). Multimedia Educativa. Recuperado de: https://innovacioneducativa.files.wordpress. com/2009/10/multimedia-educativa2.pdf

Freire, P. (1997). La educación como práctica de la libertad. México: Siglo XXI.

Latapie, I. (2007). Acercamiento al aprendizaje multimedia. Investigación Universitaria Multidisciplinaria, 6 (6), 7-14. Recuperado de:http://biblioteca.udgvirtual.udg.mx:8080/jspui/bitstream/123456789/1243/1/Acercamiento\%20al\%20aprendizaje\%20multimedia.pdf 
Hedge, T. (2000). Teaching and Learning in the Language Classroom. Oxford: New York.

McGreal, R. \& Elliott, M. (2008). Technologies of Online Learning (E-learning). En Anderson, T. (Ed.), The Theory and Practice of Online Learning. Athabasca University Press: Edmonton.

Pachano, L. \& Terán, M. (s.f.). Aprendizaje cooperativo: una experiencia constructivista en clase de matemática. Recuperado de: http://www2.uned.es/congreso-inter-educacion-intercultural/Grupo_ discusion_3/1.\%20L.pdf

Serrano, J. \& Pons, R. (2011). El Constructivismo hoy: enfoques constructivistas en educación. Revista electrónica de investigación educativa. 113 (1). Recuperado de: http://redie.uabc.mx/vol13no1/contenido-serranopons.html

Umaña, A., Salas, I., \& Berrocal, V. (s.f.). (Eds). Consideraciones para el diseño y oferta de asignaturas en línea. Recuperado de: https://www.uned.ac.cr/academica/images/vicerrectoria/documentacion/ Consideraciones-diseno-oferta-asignaturas-linea.pdf 